\title{
Out-Of-Pocket Expenditure Associated with Physical Inactivity, Excessive Weight, and Obesity in China: Quantile Regression Approach
}

\author{
Yang Zhao a,b Li He $^{c}$ Tiara Marthias d, e Marie Ishidad Kanya Anindyad \\ Allissa Desloge $^{d}$ Monique D'Souza $^{d}$ Gaofang Cao ${ }^{f}$ John Tayu Lee ${ }^{d, g}$ \\ aThe George Institute for Global Health, Faculty of Medicine, University of New South Wales, Sydney, NSW, Australia; \\ ${ }^{b}$ The George Institute for Global Health at Peking University Health Science Center, Beijing, China; ' College of \\ Physical Education and Sport, Beijing Normal University, Beijing, China; ${ }^{\mathrm{d} T h e ~ N o s s a l ~ I n s t i t u t e ~ f o r ~ G l o b a l ~ H e a l t h, ~}$ \\ The University of Melbourne, Melbourne, Melbourne, VIC, Australia; eDepartment of Public Health, Faculty of \\ Medicine, Public Health and Nursing, Universitas Gadjah Mada, Yogyakarta, Indonesia; ${ }^{f}$ College of Public Health \\ and Management, Binzhou Medical University, Yantai, China; 9Public Health Policy Evaluation Unit, Department of \\ Primary Care and Public Health, School of Public Health, Imperial College London, London, UK
}

\section{Keywords}

Out of pocket · Healthcare cost · Physical activity ·

Overweight · Obesity · China

\begin{abstract}
Introduction: Previous studies exploring associations of physical inactivity, obesity, and out-of-pocket expenditure (OOPE) mainly used traditional linear regression, and little is known about the effect of both physical inactivity and obesity on OOPE across the percentile distribution. This study aims to assess the effects of physical inactivity and obesity on OOPE in China using a quantile regression approach. Methods: Study participants included 10,687 respondents aged 45 years and older from the recent wave of the China Health and Retirement Longitudinal Study in 2015. Linear regression and quantile regression models were used to examine the association of physical activity, body weight with annual OOPE. Results: Overall, the proportion of overweight and obesity was $33.2 \%$ and $5.8 \%$, respectively. The proportion of individuals performing high-level, moderate-level, and low-level physical activity was $55.2 \%, 12.7 \%$, and $32.1 \%$,
\end{abstract}

Karger@karger.com www.karger.com/ofa

Karger!

BOPEN ACCESS
(C) 2022 The Author(s)

Published by S. Karger AG, Basel

This is an Open Access article licensed under the Creative Common Attribution-NonCommercial-4.0 International License (CC BY-NC) (http://www.karger.com/Services/OpenAccessLicense), applicable to the online version of the article only. Usage and distribution for commercial purposes requires written permission. respectively. The effects of low-level physical activity on annual OOPE were small at the bottom quantiles but more pronounced at higher quantiles. Respondents with low-level activity had an increased annual OOPE of 26.9 USD, 150.3 USD, and 1,534.4 USD, at the 10th, 50th, and 90th percentiles, respectively, compared with those with high-level activity. The effects of overweight and obesity on OOPE were also small at the bottom quantiles but more pronounced at higher quantiles. Conclusion: Interventions that improve the lifestyles and unhealthy behaviors among people with obesity and physical inactivity are likely to yield substantial financial gains for the individual and health systems in China.

(c) 2022 The Author(s).

Published by S. Karger AG, Base

\section{Introduction}

Excessive weight and physical inactivity are precursors to a plethora of adverse health outcomes, including diabetes and cardiovascular diseases like hypertension, or coronary artery disease [1-3]. Emerging evidence has found that patients with excessive weight and physical in- 
activity have higher healthcare utilization and medical cost [4-6]. In low- and middle-income countries, due to insufficient public spending on health and poor coverage of health services, patients often pay a high proportion of their medical cost out of pocket, resulting in medical impoverishment due to illness.

China, home to 1.3 billion population, underwent a rapid epidemiological transition. Compared with 1990, the most common noncommunicable diseases (NCDs), including stroke, ischemic heart disease, lung cancer, chronic obstructive pulmonary disease, and liver cancer, contributed much more to mortality and years of life lost in 2017 [7]. Historically a lean population, China has witnessed a concerning rise in overweight, obesity, and physical inactivity in recent decades [8]. It is suggested that this trend is due to rapid economic progress accompanied by urbanization over the last few decades, which has raised the standards of living for its citizens [8]. The average energy density of food has increased, with higher levels of animal fat and simple sugar consumption [8], while a lack of physical activity has resulted from a reduction in labor-intensive jobs and an increased use of motorized transport [9].

Findings from four national surveys in 2000, 2005, 2010, and 2014 among Chinese adults aged $20-59$ years estimated that the prevalence of obesity increased from $8.6 \%$ in 2000 to $10.3 \%$ in $2005,12.2 \%$ in 2010 , and $12.9 \%$ in 2014, and the prevalence rates of overweight were $37.4 \%, 39.2 \%, 40.7 \%$, and $41.2 \%$ in the year of 2000,2005 , 2010, and 2014 [10]. In addition, referring to the guidelines from the American College of Sports Medicine, Tian et al. [10] defined the recommended minimum levels of leisure-time physical activity as 150 min of moderate-intensity physical activity or $75 \mathrm{~min}$ of vigorous-intensity physical activity per week to achieve a total energy expenditure of at least 500-1,000 metabolic-equivalent-of-taskmin per week [11]. They observed that between 2000 and 2014, although the percentage of Chinese adults who met the recommendation of leisure-time physical activity slightly increased from $17.2 \%$ to $22.8 \%$, the majority of adults had insufficient physical activity [10]. Furthermore, a number of studies note similar trends in both obesity and physical inactivity in Chinese children and adolescents, suggesting that the trend will continue well into the future $[9,12-14]$. Recognizing an urgent need to improve population health, the "Healthy China 2030" plan was proposed by the Chinese government in 2016 [15]. This plan includes a number of specific targets for reducing risk factors associated with chronic disease and represents a focus on evidence-based practice, as well as

Expenditure and Physical Inactivity and Obesity a transition from emphasis on treatment to prevention of disease [15]. The plan aimed for a $30 \%$ relative reduction in premature mortality related to NCDs by the year 2030 [15]. However, a recent report has suggested that China is not on track to reach this target, especially in their most developed municipalities [16].

In low- and middle-income countries such as China, there is a heavy reliance on out-of-pocket expenditure (OOPE) to fund healthcare [17]. In 2011, 34.8\% of total health expenditure in China was paid at the cost of the individual. To address this challenge, the "Healthy China 2030 " plan aims to decrease OOPE to $25 \%$ in line with other high-income countries [15]. High OOPE on healthcare is problematic as it has shown to be a barrier for patients in seeking healthcare, thus leading to worse health outcomes [17]. It is known to be particularly detrimental to those with chronic illness, who are much more likely to suffer from catastrophic health expenditure and impoverishment as a result of these costs [18]. In 2012, the rates of catastrophic health expenditure and impoverishment in China were estimated to be $13 \%$ and $7.5 \%$, respectively [18]. Similarly, one 2012 study using nationally representative data estimated physical inactivity to be responsible for $15 \%$ of total healthcare costs in China [6], while overweight and obesity accounted for 3\% of China's total healthcare costs from 2000 to 2009 [5].

There is evidence that physical inactivity and obesity are risk factors leading to higher OOPE in China [19, 20], but all of these studies have used traditional linear regression and were limited by a small sample from major cities in China. For example, a study of university retirees from Beijing, China, found that overweight and obesity were associated with an increased OOPE of $13 \%$ and $33 \%$, respectively, compared to healthy weight individuals [19]. Little is known about the effect of both physical inactivity and obesity on OOPE across the percentile distribution. Unlike traditional regression methods, such as the ordinary least squares regression or the generalized linear model, that focus on population average/mean effects, quantile regression models look at the effect of physical inactivity and obesity on healthcare costs across the outcome distribution. Alternative estimation strategies using quantile regression analysis have been increasingly adopted in health systems research to investigate the associations between outcomes of interest and the explanatory variables across the distribution of a given dependent variable [21].

To fill this important evidence gap, this study will use nationally representative data from the 2015 China Health and Retirement Longitudinal Study (CHARLS) looking 
at Chinese adults $>45$ years. The study will assess the effect of (a) physical activity (high/moderate/low) and (b) body mass index (BMI, normal/overweight/obese) on the 10th, 25th, 50th, and 90th percentiles of OOPE, after controlling for a number of covariates. To our knowledge, this will be the first study to assess the effects of physical inactivity and obesity on OOPE in China using a quantile regression approach.

\section{Materials and Methods}

\section{Materials}

This study used the most recent wave of data from the CHARLS conducted in 2015. The study collected high-quality data from a nationally representative sample of Chinese residents aged 45 and older, using multi-stage stratified probability-proportionate-tosize sampling. The total sample size of the CHARLS baseline survey was 17,708 individual respondents. Ongoing follow-up surveys were conducted once every 2 years. A detailed description of the survey objectives and methods has been reported elsewhere [22]. For this study, we identified 14,576 respondents without loss to follow-up. After removing respondents' BMI $<18.5 \mathrm{~kg} / \mathrm{m}^{2}$ and individuals with missing values of dependent variables and covariates, our final sample had 10,687 respondents (73.3\% of 14,576). Weight status was analyzed using this entire sample, and the level of physical activity was analyzed among 5,713 participants who reported their weekly physical exercise time.

\section{Measures}

The level of physical activity was measured by a modified version of the International Physical Activity Questionnaire, which assessed total physical activity [23], including the frequency of weekly physical exercise (days of physical activity at least $10 \mathrm{~min}$ ) and physical activity intensity, including walking, moderate, and vigorous physical activity.

Information on physical activity was assessed with two items asking "Did you walk or perform moderate and vigorous physical activity for 10 min or longer during last 7 days"?, "How many of the last 7 days did you walk, or perform moderate, and vigorous physical activity for 10 min or longer"? A new variable was computed to classify participants into three groups: (1) high-level physical activity (practice of vigorous physical activity for $10 \mathrm{~min}$ or longer $\geq 3$ days/week, or moderate physical activity for $10 \mathrm{~min}$ or longer $\geq 5$ days/week); (2) moderate-level physical activity (practice of vigorous physical activity for $10 \mathrm{~min}$ or longer 1-2 days/week, or moderate physical activity for $10 \mathrm{~min}$ or longer 1-4 days/week); and (3) low-level physical activity/physical inactivity (none weekly physical exercise and/or only walking during last week).

In terms of overweight and obesity, the CHARLS provided respondents' BMI calculated from measured weight in kilograms and height in meters $\left(\mathrm{kg} / \mathrm{m}^{2}\right)$. We classified the weight status into three categories according to the World Health Organization definition: normal weight (BMI: $18.5-24.9 \mathrm{~kg} / \mathrm{m}^{2}$ ), overweight (BMI: $25-29.9 \mathrm{~kg} / \mathrm{m}^{2}$ ), and obesity (BMI: $\geq 30 \mathrm{~kg} / \mathrm{m}^{2}$ ) [24].
Table 1. Characteristics of sample in 2015

\begin{tabular}{|c|c|c|c|}
\hline Characteristic & $N$ & $\begin{array}{l}\text { Unweighted, } \\
\%\end{array}$ & $\begin{array}{l}\text { Weighted, } \\
\%\end{array}$ \\
\hline Total & 10,687 & 100.0 & 100.0 \\
\hline \multicolumn{4}{|l|}{ Age, year } \\
\hline $45-54$ & 3,430 & 32.1 & 31.8 \\
\hline $55-64$ & 3,930 & 36.8 & 37.1 \\
\hline $65-74$ & 2,537 & 23.7 & 23.1 \\
\hline 75 and above & 790 & 7.4 & 8.0 \\
\hline \multicolumn{4}{|l|}{ Gender } \\
\hline Male & 5,036 & 47.1 & 47.5 \\
\hline Female & 5,651 & 52.9 & 52.5 \\
\hline \multicolumn{4}{|l|}{ Marital status } \\
\hline Married and partnered & 9,381 & 87.8 & 87.6 \\
\hline Unmarried and other & 1,306 & 12.2 & 12.4 \\
\hline \multicolumn{4}{|l|}{ Education status } \\
\hline Illiterate & 4,521 & 42.3 & 39.4 \\
\hline Primary school & 2,854 & 26.7 & 26.7 \\
\hline Secondary school & 2,216 & 20.7 & 21.7 \\
\hline College and above & 1,096 & 10.3 & 12.2 \\
\hline \multicolumn{4}{|l|}{ Residence place } \\
\hline Urban & 4,014 & 37.6 & 45.1 \\
\hline Rural & 6,673 & 62.4 & 54.9 \\
\hline \multicolumn{4}{|l|}{ Region } \\
\hline East & 4,007 & 37.5 & 40.6 \\
\hline Central & 4,135 & 38.7 & 36.8 \\
\hline West & 2,545 & 23.8 & 22.5 \\
\hline \multicolumn{4}{|l|}{ PCE, quartile } \\
\hline Q1, the lowest & 2,674 & 25.0 & 22.7 \\
\hline Q2 & 2,671 & 25.0 & 24.4 \\
\hline Q3 & 2,671 & 25.0 & 26.0 \\
\hline Q4, the highest & 2,671 & 25.0 & 26.9 \\
\hline \multicolumn{4}{|l|}{ Social health insurance } \\
\hline No & 1,749 & 16.4 & 17.1 \\
\hline Yes & 8,938 & 83.6 & 82.9 \\
\hline \multicolumn{4}{|l|}{ BMI } \\
\hline Normal & 6,598 & 61.7 & 61.0 \\
\hline Overweight & 3,441 & 32.2 & 33.2 \\
\hline Obesity & 648 & 6.1 & 5.8 \\
\hline \multicolumn{4}{|l|}{ Physical activity } \\
\hline High-level PA & 2,930 & 55.6 & 55.2 \\
\hline Moderate-level PA & 658 & 12.5 & 12.7 \\
\hline Low-level PA & 1,679 & 31.9 & 32.1 \\
\hline
\end{tabular}

BMI, body mass index.

The primary outcome variable was annual OOPE, defined as the sum of direct payments for outpatient and inpatient care provided during the last year, after reimbursement from health insurance. Since the OOPE for outpatient care is measured 1 month at a time, this study calculated the 1-year outpatient care costs by multiplying the 1 -month measurement by 12 . We included the following variables as covariates in the regression analyses: age, gender, marital status (married and partnered, unmarried and others), level of education (illiterate, primary school, secondary school, college and above), place of residence (rural, urban), geographical 
Table 2. Out-of-pocket health expenditure by the weight status and physical activity group

\begin{tabular}{|c|c|c|c|c|c|c|c|c|c|}
\hline & proportion & $95 \%$ & & mean & $95 \% \mathrm{Cl}$ & & mean & $95 \% \mathrm{Cl}$ & \\
\hline High-level PA & 26.1 & 24.6 & 27.7 & 326.3 & 266.2 & 386.3 & $1,248.6$ & $1,030.5$ & $1,466.7$ \\
\hline Moderate-level PA & 27.8 & 24.5 & 31.0 & 531.8 & 185.4 & 878.3 & $1,916.2$ & 685.7 & $3,146.7$ \\
\hline Normal & 26.3 & 25.3 & 27.4 & 437.1 & 370.3 & 503.9 & $1,659.3$ & $1,414.7$ & $1,904.0$ \\
\hline Overweight & 27.9 & 26.4 & 29.4 & 552.8 & 441.0 & 664.7 & $1,981.5$ & $1,594.7$ & $2,368.3$ \\
\hline Obesity & 30.9 & 27.3 & 34.4 & 480.4 & 359.2 & 601.6 & $1,556.5$ & $1,206.4$ & $1,906.5$ \\
\hline
\end{tabular}

OOPE, out-of-pocket expenditure.

region (east, central, and west), household economic status quartiles (yearly per capita household consumption expenditure $[\mathrm{PCE}]$ ), and social health insurance (yes, no).

\section{Statistical Approach}

We summarized the mean of annual OOPE across BMI and physical inactivity groups. This study assessed the effect of physical inactivity and obesity on OOPE using a linear regression and quantile regression model. For individuals with positive OOPE (expenditures $>0$ USD), linear regression models were used to examine the overall effects of physical inactivity and obesity on OOPE. Quantile regression analysis was also performed to estimate the impact of physical inactivity and obesity on OOPE at the 10 th, 25th, 50th, 75th, and 90th percentiles. Analogous to ordinary least squares regression, quantile regression estimates the median or other quantiles of an outcome variable associated with a set of predictors and covariates without the assumptions of normality and homoscedasticity of the underlying distribution [25-27]. Quantile regression is robust to outliers because it allows for studying the full distribution of the outcome variable and is suitable for modeling outcomes that are highly skewed or not normally distributed $[21,28]$. The coefficients at lower percentiles (10th, 25th percentiles) present the association of physical inactivity and obesity with OOPE in those individuals with low health expenditures, while upper percentiles (75th, 90th percentiles) reflect the association on those with higher health expenditures. We also estimated the effect of physical inactivity and obesity with the individual as a predicting variable in our regression analysis. All statistical analyses were conducted using Stata software 15.0 (Stata Corp., College Station, TX, USA).

\section{Results}

We analyzed data from 10,687 respondents. Table 1 presents the respondents' socioeconomic and demographic characteristics. The median age of participants was 60 years (IQR 52-66) in 2015. There was a slightly higher percentage of female (52.5\%) than male respondents. Most of the respondents were married (87.6\%) and resided in rural areas (54.9\%). Only $33.9 \%$ of the respondents had attained a level of education higher than primary school, and $82.9 \%$ of the respondents were enrolled in social health insurance in China. Overall, the proportion of overweight and obesity was $33.2 \%$ and $5.8 \%$, respectively. The proportion of individuals performing high-level physical activity, moderate-level physical activity, and low-level physical activity was 55.2\%, 12.7\%, and $32.1 \%$, respectively.

Table 2 shows the proportion and average annual OOPE across the weight status and physical activity groups. Of the total participants, $27.1 \%$ experienced an occurrence of OOPE during the last year. Overall, the mean OOPE was 477 USD in our total sample and 1,759 USD among participants with positive OOPE. Obesity was associated with a higher incidence of incurring any OOPE last year (30.9\%) compared to normal weight persons (26.3\%). Low-level physical activity was associated with a higher incidence of incurring any OOPE last year (28.3\%) compared to highlevel physical activity (26.1\%). Among people with positive OOPE, physical inactivity and overweight were associated with a substantially greater OOPE.

\section{Results of Quantile Regression Analysis}

The result of quantile regression analysis (among those experiencing a positive OOPE) suggested that physical inactivity was significantly associated with greater OOPE at both higher percentiles and lower percentiles of OOPE spending (Fig. 1). The OOPE attributable to overweight (top) and obesity (bottom) over the distribution of the OOPE is depicted in Figure 2. Variations in OOPE attribut- 


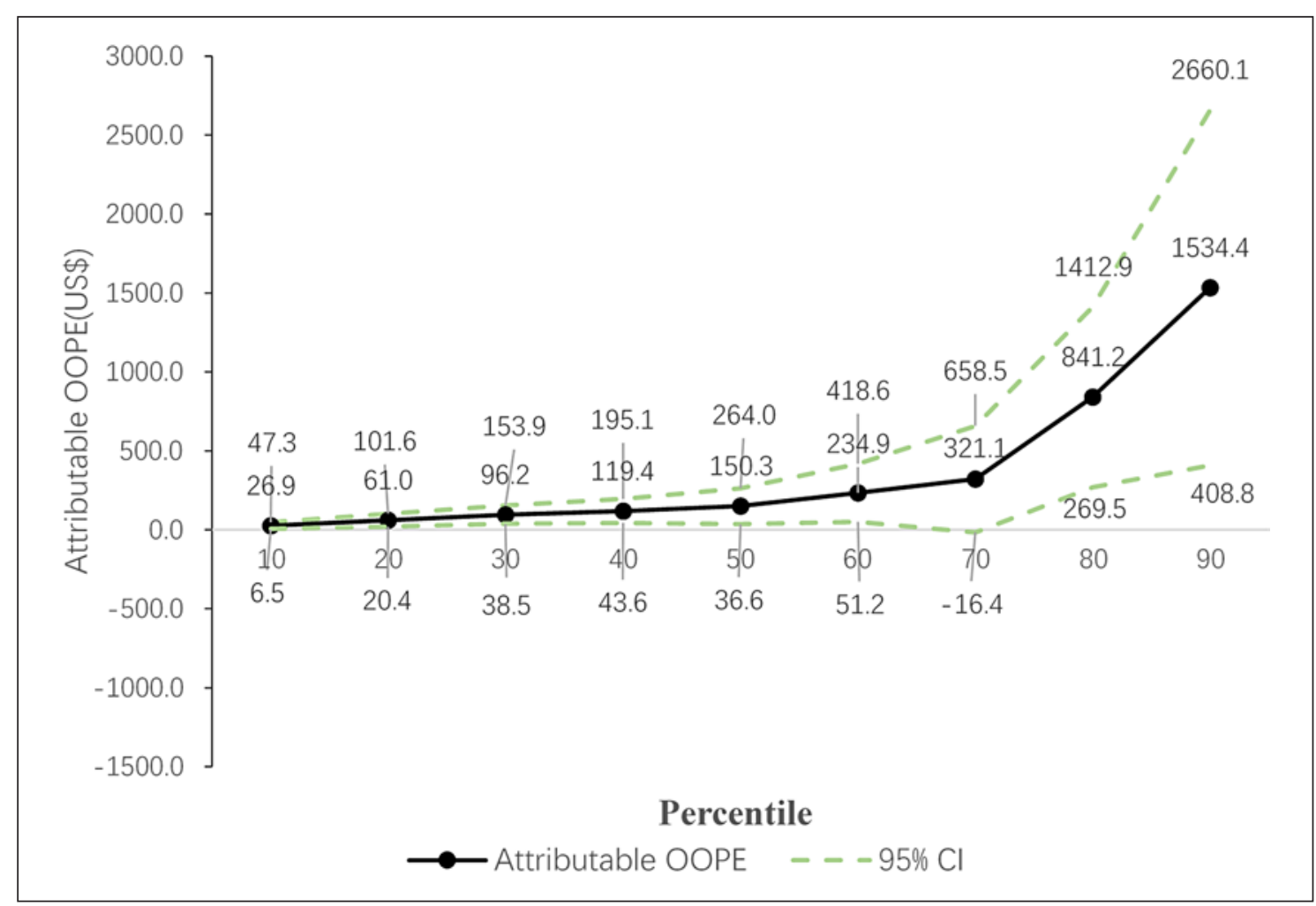

Fig. 1. Distribution of adjusted OOPE associated with physical inactivity by percentile of OOPE.

able to overweight and obesity became more pronounced as expenditure approached the upper percentiles.

Table 3 shows that the effects of low-level physical activity on annual OOPE were small at the bottom quantiles but more pronounced at higher quantiles. Respondents with low-level activity had an increased annual OOPE of 26.9 USD, 150.3 USD, and 1,534.4 USD, at the 10th, 50th, and 90th percentiles, respectively, compared with those with high-level activity. The difference in OOPE is greater at higher percentiles of the OOPE distribution, but with wide confidence intervals. There is no statistically significant association of moderate-level activity with annual OOPE.

Table 4 shows that annual OOPE increased due to obesity at the 10th, 25th, 50th, and 75th quantiles, compared with those individuals with normal weight after adjusting for covariates. The annual OOPE attributable to obesity was higher than OOPE attributable to overweight in all quantiles of the distribution except the 90th quantile, while OOPE attributable to overweight and obesity was not significant in most quantiles of the distribution except for the group of overweight at the 50th quantile and the groups of obesity at the 25th and 50th quantiles. The effects of overweight and obesity on OOPE were also small at the bottom quantiles but more pronounced at higher quantiles. The difference in OOPE is greater at higher percentiles of the OOPE distribution, but with wide confidence intervals.

\section{Discussion}

The association of obesity and physical activity with OOPE in a large nationally representative sample in China in the present study is similar with that of previous research from the USA, Australia, and some European countries $[4,29]$. Consistent to previous studies, it highlights the potential economic burden of the growing prevalence of physical inactivity, excessive weight, and obesity [30-36]. While only $8.1 \%$ of our sample was uninsured, the share of OOPE remained high, with almost $30 \%$ of people with low physical activity or obesity still experiencing an occurrence of OOPE. Our results support the evidence that accessibility of health insurance benefit packages for older adults is still relatively low in China [37]. 


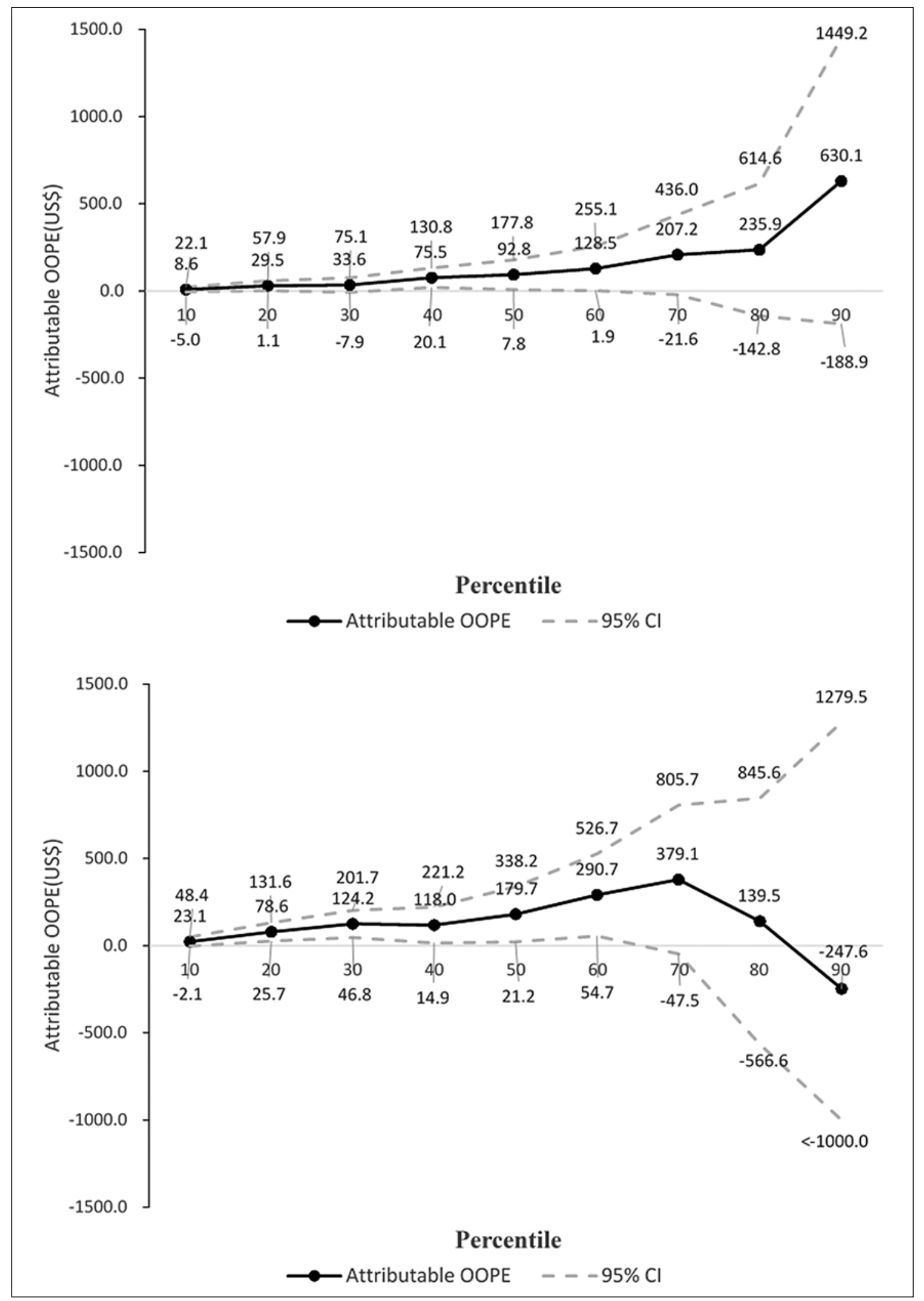

Fig. 2. Distribution of adjusted OOPE associated with overweight (top) and obesity (bottom) by percentile of OOPE. 


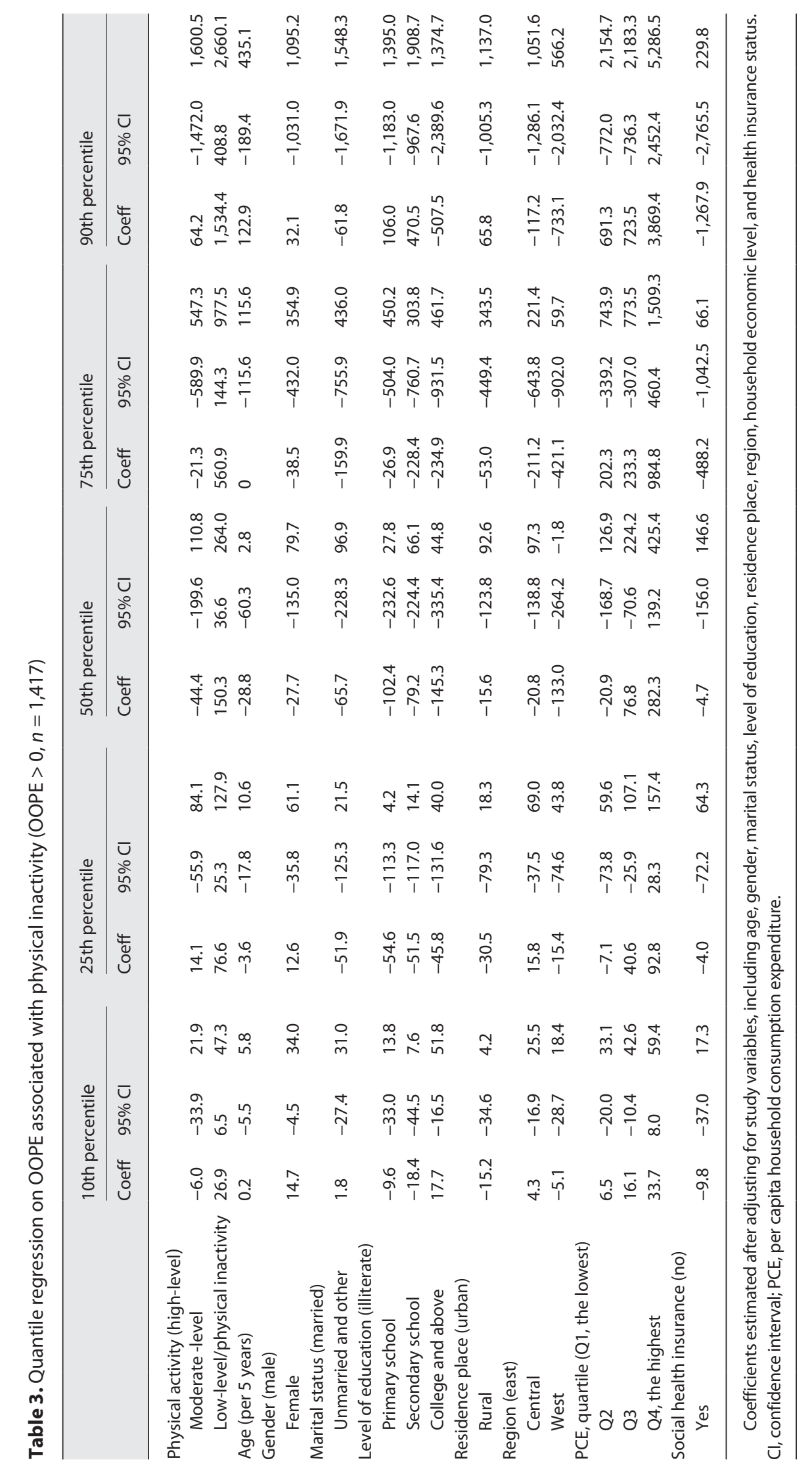




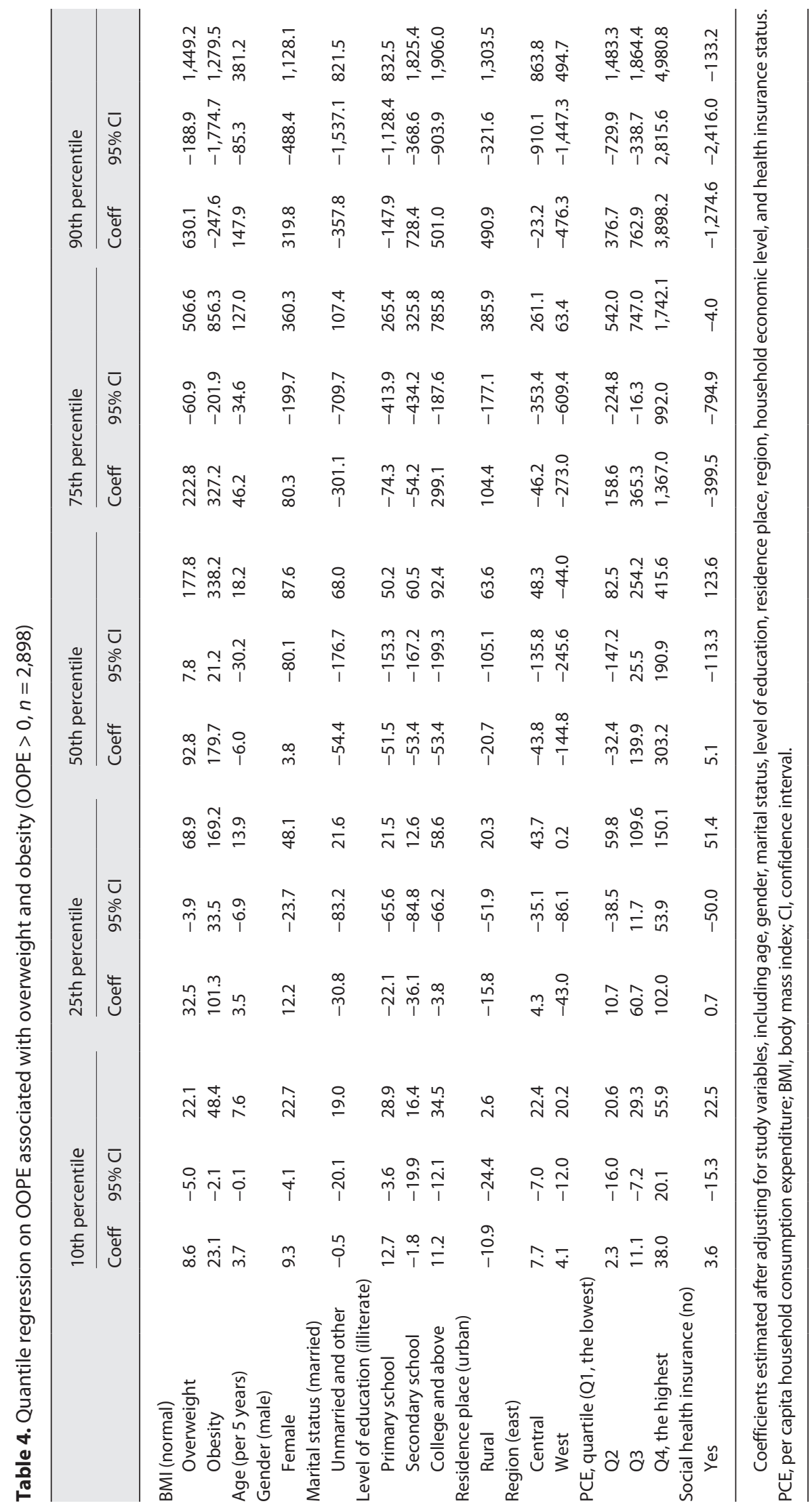


With the present sample of adults aged at 45 years or older, engaging in high-level physical activity (practice of vigorous-intensity physical activity for $10 \mathrm{~min}$ or longer $\geq 3$ days/week, or moderate-intensity physical activity for 10 min or longer $\geq 5$ days/week frequency of their physical activity) was found to have a decreased annual OOPE, compared with those inactive. This is similar to previous findings. In a study of 94,267 adults from 16 European countries, Dallmeyer et al. [29] found that if a person is physically active once a week, annual OOPE is reduced by $17.7 \%$ compared to someone who is never active. For physical activity more than once a week, this effect decreases to $15.3 \%$. For physical activity less than once a week, it is reduced to $12.7 \%$ [29]. Likewise, in China, Zhang and Chaaban [6] estimated the medical cost attributable to physical inactivity reached 24.3 billion Yuan $(3.5$ billion USD) in 2008. Similarly, a previous study exploring the association of physical activity and health expenditures among elderly patients with coronary heart diseases in Dongfeng-Tongji, China, found that people with no or light physical activity had significantly longer hospital stays and had a greater inpatient and outpatient cost [38].

Moreover, the study by Qin and Pan [5] found that the annual medical cost attributable to overweight and obesity in China was 24.35 billion Yuan. A reasonable explanation of the higher OOPE increase with physical inactivity and obesity may be that both physical inactivity and obesity are associated with a higher risk of developing five major NCDs in China, including coronary heart disease, stroke, hypertension, cancer, and type 2 diabetes [6], which consequently impose a substantial financial burden on individuals, family, and society. Therefore, continued nationwide interventions are needed to promote physical activity and decrease the prevalence of overweight and obesity in China so as to decrease the healthcare cost. Given the benefits of moderate- to high-intensity physical activity to weight management and reduction, promotion of sufficient physical activity participation is recommended as the first priority. In addition, the government must ensure appropriate financial support to mitigate the economic burden among the older population [39].

There is worldwide acceptance among medical authorities that physical inactivity and excessive weight or obesity are increasingly being viewed as the two of the greatest threats to public health in both developed and developing countries today [40-62]. Key national and global policy initiatives have attempted to address the issues mentioned above, including Healthy China 2030s vision and the World Health Organization's Global NCD Target that calls for a $10 \%$ reduction in the prevalence of physical inactivity by $2025[63,64]$. To achieve this goal, healthcare settings could be used to provide comprehensive assessment and promotion for physical activity among adult patients. Physicians should collaborate with other healthcare professionals such as physical therapists and nurses, integrate assessment of physical activity into vital sign assessment or general medical checkups, prescribe exercise for patients especially those with comorbid conditions including overweight/obesity, and monitor the compliance and outcomes of exercise and dietary changes [65]. Certain types of exercise that are popular among middle-aged and older members of the Chinese population, such as tai chi and dancing, have been found to reduce the risk of NCDs $[66,67]$. However, lifestyle changes, such as sedentary living conditions and rapid industrialization, have limited the uptake of such traditional exercise [67], and thus, creating conducive social and physical environments for these activities is imperative. Further, to improve the level of physical activity and prevent the onset of chronic diseases, future promotions could be customized for older adults to encourage sufficient physical activity in an otherwise sedentary population. Finally, as physical inactivity is correlated with additional financial burden, health promotion could stress the potential economic savings of being physically active, which has been shown to be effective among the elderly population [68].

\section{Strengths and Limitations}

To our knowledge, this is the first study that examined OOPE in relation to obesity and physical activity using a quantile regression approach that can reflect the variations in the impact of obesity and physical inactivity across the percentile distribution. There is no current study, which confirms the reverse or bidirectional causality between levels of physical activity and obesity. Therefore, we examined the associations of both physical inactivity and obesity with health service expenditures, which let readers compare the results of analyses of two risk factors. However, there are some limitations that should be acknowledged. First, the use of self-reported height and weight to calculate BMI and assess physical activity lacks the accuracy of the measured data. Existing literature suggests that the self-reported BMI is likely underestimated especially among obese individuals $[69,70]$, while self-reporting of physical activity is likely over-reported [71]. This reporting bias impedes the precise estimation of outcomes. Second, OOPE might not be attributable to the health conditions associated with obesity or physical inactivity. OOPE includes the costs that are not specific to the health conditions associated with obesity and physical inactivity such 
as infectious diseases (e.g., pneumonia) and physical injuries. Therefore, our results on the cost burden of obesity and physical inactivity might be overestimated. Third, some covariates, such as social health insurance and marital status, were included as dichotomous variables for performing quantile regressions due to the limited sample in CHARLS. Finally, the cross-sectional nature of study limits the ability to prove the causal relationships. Future study should use longitudinal study design to explore the effect of obesity and physical inactivity on OOPE attributable to diseases associated with these risk factors.

\section{Conclusion}

In conclusion, this study provides important evidence from a nationally representative sample that physical inactivity and overweight are associated with a substantially greater OOPE among Chinese adults with positive OOPE. The impact of physical inactivity on treatment cost gradually increases as costs approach the upper quantile of treatment costs. Interventions that improve the lifestyles and unhealthy behaviors among people with obesity and physical inactivity are likely to yield substantial financial gains for the individual and health systems in China.

\section{Acknowledgments}

We gratefully acknowledge the CHARLS team for providing data and training in using the datasets. We are grateful to the students who participated in the survey for their cooperation. The authors thank all volunteers and staff involved in this research.

\section{Statement of Ethics}

The Biomedical Ethics Review Committee of Peking University approved the CHARLS, and all interviewees were required to provide written informed consent. The ethical approval number was IRB00001052-11015.

\section{Conflict of Interest Statement}

The authors declare that they have no competing interests.

\section{Funding Sources}

This work was supported by the National Natural Science Foundation of China Youth Science Foundation (81602869). The funder played no role in the study design, data collection or analysis, or preparation of the manuscript.

\section{Author Contributions}

Y.Z. and J.T.L. conceived and designed the study. Y.Z., L.H., and G.C. did the initial analysis and supervised data analysis. Y.Z. wrote the first draft of the paper, and L.H., T.M., M.I., K.A., A.D., M.D., J.T.L., and G.C. critically revised the first draft. All authors reviewed and approved the final version of the paper submitted for publication.

\section{Data Availability Statement}

The datasets generated during and/or analyzed during the current study are available in the CHARLS repository on reasonable request, http://charls.pku.edu.cn/pages/data/111/zh-cn.html

\section{References}

1 Colpani V, Baena CP, Jaspers L, van Dijk GM, Farajzadegan Z, Dhana K, et al. Lifestyle factors, cardiovascular disease and all-cause mortality in middle-aged and elderly women: a systematic review and meta-analysis. Eur J Epidemiol. 2018:33(9):831-45.

2 Global Burden of Metabolic Risk Factors for Chronic Diseases Collaboration (BMI mediated effects); Lu Y, Hajifathalian K, Ezzati M, Woodward M, Rimm EB, et al. Metabolic mediators of the effects of body-mass index, overweight, and obesity on coronary heart disease and stroke: a pooled analysis of 97 prospective cohorts with 1.8 million participants. Lancet. 2014;383(9921):970-83.

3 Kyu HH, Bachman VF, Alexander LT, Mumford JE, Afshin A, Estep K, et al. Physical activity and risk of breast cancer, colon cancer, diabetes, ischemic heart disease, and ischemic stroke events: systematic review and dose-response meta-analysis for the Global Burden of Disease Study 2013. BMJ. 2016; 354:i3857.

4 Brown WJ, Hockey R, Dobson AJ. Physical activity, body mass index and health care costs in mid-age Australian women. Aust N Z J Public Health. 2008;32(2):150-5.

5 Qin X, Pan J. The medical cost attributable to obesity and overweight in China: estimation based on longitudinal surveys. Health Econ. 2016;25(10):1291-311.

6 Zhang J, Chaaban J. The economic cost of physical inactivity in China. Prev Med. 2013; 56(1):75-8.

7 Zhou M, Wang H, Zeng X, Yin P, Zhu J, Chen $\mathrm{W}$, et al. Mortality, morbidity, and risk factors in China and its provinces, 1990-2017: a systematic analysis for the Global Burden of Disease Study 2017. Lancet. 2019;394(10204): 1145-58.
8 Parízková J, Chin MK, Chia M, Yang JZ. An international perspective on obesity, health and physical activity: current trends and challenges in China and Asia. J Exerc Sci Fit. 2007;5:7-23.

$9 \mathrm{Wu}$. Overweight and obesity in China. BMJ. 2006;333(7564):362-3.

10 Tian Y, Jiang C, Wang M, Cai R, Zhang Y, He $\mathrm{Z}$, et al. BMI, leisure-time physical activity, and physical fitness in adults in China: results from a series of national surveys, 2000-14. Lancet Diabetes Endocrinol. 2016;4(6):487-97.

11 Garber CE, Blissmer B, Deschenes MR, Franklin BA, Lamonte MJ, Lee IM, et al. American College of Sports Medicine position stand. Quantity and quality of exercise for developing and maintaining cardiorespiratory, musculoskeletal,and neuromotor fitness in apparently healthy adults: guidance for prescribing exercise. Med Sci Sports Exerc. 2011;43(7):1334-59. 
12 Ying-Xiu Z, Shu-Rong W. Secular trends in body mass index and the prevalence of overweight and obesity among children and adolescents in Shandong, China, from 1985 to 2010. J Public Health. 2012;34(1):131-7.

13 Ji CY, Cheng TO. Epidemic increase in overweight and obesity in Chinese children from 1985 to 2005. Int J Cardiol. 2009;132(1):1-10.

14 Dong Y, Jan C, Ma Y, Dong B, Zou Z, Yang Y, et al. Economic development and the nutritional status of Chinese school-aged children and adolescents from 1995 to 2014: an analysis of five successive national surveys. Lancet Diabetes Endocrinol. 2019;7(4):288-99.

15 Central People's Government of the People's Republic of China. Healthy China initiative (2019-2030). Available from: http://www. gov.cn/xinwen/2019-07/15/content_5409694.htm (accessed July 23, 2019).

16 Tan X, Wu Q, Shao H. Global commitments and China's endeavors to promote health and achieve sustainable development goals. J Health Popul Nutr. 2018;37(1):8.

17 Lee JT, Hamid F, Pati S, Atun R, Millett C. Impact of noncommunicable disease multimorbidity on healthcare utilization and outof-pocket expenditures in middle-income countries: cross sectional analysis. PLoS One. 2015;10(7): 0127199.

18 Li Y, Wu Q, Xu L, Legge D, Hao Y, Gao L, et al. Factors affecting catastrophic health expenditure and impoverishment from medical expenses in China: policy implications of universal health insurance. Bull World Health Organ. 2012;90(9):664-71.

19 Jiang N, Yu H, An R. Body weight status and health-care expenditure among university retirees in Beijing, China. Australas J Ageing. 2017;36(3):E21-7.

$20 \mathrm{Yu} \mathrm{H}$, Schwingel A. Associations between sedentary behaviour, physical activity, and out-of-pocket health care expenditure: evidence from Chinese older adults. J Aging Phys Act. 2018:1-8. Epub ahead of print.

21 Koenker R. Quantile regression (econometric society monographs). Cambridge: Cambridge University Press; 2005.

22 Zhao Y, Hu Y, Smith JP, Strauss J, Yang G. Cohort profile: the China health and retirement longitudinal study (CHARLS). Int J Epidemiol. 2014;43(1):61-8.

23 The International Physical Activity Questionnaire Group. IPAQ scoring protocol-International Physical Activity Questionnaire. Available from: https://sites.google.com/site/ theipaq/scoringprotocol (accessed March 26, 2018).

24 World Health Organization Expert Consultation. Appropriate body-mass index for Asian populations and its implications for policy and intervention strategies. Lancet. 2004; 363(9403): 157

25 Firpo S, Fortin NM, Lemieux T. Unconditional quantile regressions. Econometrica. 2009;77:953-73.

26 Koenker R, Hallock KF. Quantile regression. J Econ Perspect. 2001;15(4):143-56.
27 Gebregziabher M, Lynch CP, Mueller M, Gilbert GE, Echols C, Zhao Y, et al. Using quantile regression to investigate racial disparities in medication non-adherence. BMC Med Res Methodol. 2011;11:88.

28 Korn FL, Graubard BI. Basic survey methodology. In: Korn FL, Graubard BI, editors. Analysis of health surveys. New York: John Wiley \& Sons; 1999. p. 32-3.

29 Dallmeyer S, Wicker P, Breuer C. The relationship between physical activity and out-ofpocket health care costs of the elderly in Europe. Eur J Public Health. 2020 Aug 1;30(4): $628-32$.

30 Jakovljevic M, Sugahara T, Timofeyev Y, Rancic N. Predictors of (in)efficiencies of healthcare expenditure among the leading Asian economies: comparison of OECD and nonOECD nations. Risk Manag Healthc Policy. 2020;13:2261-80.

31 Jakovljevic M, Timofeyev Y, Ranabhat CL, Fernandes PO, Teixeira JP, Rancic N, et al. Real GDP growth rates and healthcare spending: comparison between the G7 and the EM7 countries. Global Health. 2020;16(1):64

32 Jakovljevic M, Matter-Walstra K, Sugahara T, Sharma T, Reshetnikov V, Merrick J, et al. Cost-effectiveness and resource allocation (CERA) 18 years of evolution: maturity of adulthood and promise beyond tomorrow. Cost Eff Resour Alloc. 2020;18(1):15.

33 Godman B, Haque M, Kumar S, Islam S, Charan J, Akter F, et al. Current utilization patterns for long-acting insulin analogues including biosimilars among selected Asian countries and the implications for the future. Curr Med Res Opin. 2021;37(9):1529-45.

34 Jakovljevic M, Jakab M, Gerdtham U, McDaid D, Ogura S, Varavikova E, et al. Comparative financing analysis and political economy of noncommunicable diseases. J Med Econ. 2019;22(8):722-7.

35 Hills AP, Mokhtar N, Brownie S, Byrne NM. Childhood obesity in Asia: the value of accurate body composition methodology. Asia Pac J Clin Nutr. 2014;23(3):339-43.

36 Katzmarzyk PT, Janssen I. The economic costs associated with physical inactivity and obesity in Canada: an update. Can J Appl Physiol. 2004;29(1):90-115.

37 Han Y, He Y, Lyu J, Yu C, Bian M, Lee L. Aging in China: perspectives on public health. J Glob Health. 2020;4(1):11-7.

38 Wang F, Zhang LY, Zhang P, Cheng Y, Ye BZ, He MA, et al. Effect of physical activity on hospital service use and expenditures of patients with coronary heart disease: results from Dongfeng-Tongji cohort study in China. Curr Med Sci. 2019;39(3):483-92.

39 Sun J, Deng S, Xiong X, Tang S. Equity in access to healthcare among the urban elderly in China: does health insurance matter? Int J Health Plann Manage. 2014;29(2):e127-44.

40 Wadden TA, Brownell KD, Foster GD. Obesity: responding to the global epidemic. J Consult Clin Psychol. 2002;70:510-25.
41 Ding D, Lawson KD, Kolbe-Alexander TL, Finkelstein EA, Katzmarzyk PT, van Mechelen $\mathrm{W}$, et al. The economic burden of physical inactivity: a global analysis of major noncommunicable diseases. Lancet. 2016; 388(10051):1311-24.

42 Powell KE, Paluch AE, Blair SN. Physical activity for health: what kind? How much? How intense? On top of what? Annu Rev Public Health. 2011;32(1):349.

43 Müller-Riemenschneider F, Reinhold T, Berghöfer A, Willich SN. Health-economic burden of obesity in Europe. Eur J Epidemiol. 2008;23(8):499-509.

44 Kengne AP, Sobngwi E, Echouffo-Tcheugui JB, Mbanya JC. New insights on diabetes mellitus and obesity in Africa-part 2: prevention, screening and economic burden. Heart. 2013; 99(15):1072-7.

45 Stephenson J, Bauman A, Armstrong T, Smith B, Bellew B. The cost of illness attributable to physical inactivity in Australia: a preliminary study. Commonwealth Department of Health and Aged Care; 2000.

46 Medina C, Coxson P, Penko J, Janssen I, Bautista-Arredondo S, Barquera S, et al. Cardiovascular and diabetes burden attributable to physical inactivity in Mexico. Cardiovasc Diabetol. 2020;19(1):99.

47 Scarborough P, Bhatnagar P, Wickramasinghe KK, Allender S, Foster C, Rayner M. The economic burden of ill health due to diet, physical inactivity, smoking, alcohol and obesity in the UK: an update to 2006-07 NHS costs. J Public Health. 2011;33(4):527-35.

48 Jakovljevic M, Sharma T, Kumagai N, Ogura S. Editorial: NCDs - core challenge of modern day health care establishments. Front Public Health. 2021;9:692926.

49 Global Burden of Disease Child and Adolescent Health Collaboration; Kassebaum N, Kyu HH, Zoeckler L, Olsen HE, Thomas K, et al. Child and adolescent health 1990 to 2015: findings from global burden of diseases, injuries, and risk factors (GBD) 2015 study. 2017; 171(6):573-92.

50 Jakovljevic MB, Milovanovic O. Growing burden of non-communicable diseases in the emerging health markets: the case of BRICS. Front Public Health. 2015;3:65.

51 Dubbert PM, Carithers T, Sumner AE, Barbour KA, Clark BL, Hall JE, et al. Obesity, physical inactivity, and risk for cardiovascular disease. Am J Med Sci. 2002;324(3):116-26.

52 Haapanen-Niemi N, Miilunpalo S, Pasanen M, Vuori I, Oja P, Malmberg J. Body mass index, physical inactivity and low level of physical fitness as determinants of all-cause and cardiovascular disease mortality: 16 year follow-up of middle-aged and elderly men and women. Int J Obes. 2000;24(11):146574.

53 Twells LK, Gregory DM, Reddigan J, Midodzi WK. Current and predicted prevalence of obesity in Canada: a trend analysis. CMAJ Open. 2014;2(1):E18-26. 
54 Ding L, Liang Y, Tan ECK, Hu Y, Zhang C, Liu Y, et al. Smoking, heavy drinking, physical inactivity, and obesity among middle-aged and older adults in China: cross-sectional findings from the baseline survey of CHARLS 2011-2012. BMC Public Health. 2020;20: 1062.

55 Li Y, Teng D, Shi X, Teng X, Teng W, Shan Z, et al. Changes in the prevalence of obesity and hypertension and demographic risk factor profiles in China over 10 years: two national cross-sectional surveys. Lancet Reg Health West Pac. 2021;15:100227.

56 Ramachandran A, Snehalatha C. Rising burden of obesity in Asia. J Obes. 2010;2010: 868573.

57 Li M, Dibley MJ. Child and adolescent obesity in Asia. Chest. 2012.

58 Ramachandran A, Chamukuttan S, Shetty SA, Arun N, Susairaj P. Obesity in Asia: is it different from rest of the world. Diabetes Metab Res Rev. 2013;28 Suppl 2:47-51.

59 Uijtdewilligen L, Waters CN, Müller-Riemenschneider F, Lim YW. Preventing childhood obesity in Asia: an overview of intervention programmes. Obes Rev. 2016;17(11) 1103-15.

60 Lee A, Ho MM, Keung VM. Global epidemics of childhood obesity is hitting a "less industrialized" corner in Asia: a case study in Macao. Int J Pediatr Obes. 2011;6(2 Pt 2):e252-6.
61 Wu Y, Wang L, Zhu J, Gao L, Wang Y. Growing fast food consumption and obesity in Asia: challenges and implications. Soc Sci Med. 2020;269(5):113601.

62 Lindsay AC, Sitthisongkram S, Greaney ML, Wallington SF, Ruengdej P. Non-responsive feeding practices, unhealthy eating behaviors, and risk of child overweight and obesity in Southeast Asia: a systematic review. Int J Environ Res Public Health. 2017;14(4):436.

63 Foster C, Shilton T, Westerman L, Varney J, Bull F. World Health Organization to develop global action plan to promote physical activity: time for action. Br J Sports Med. 2018; 52(8):484-5.

64 World Health Organization. Healthy China 2030 (from vision to action). Available from: http: //www.who.int/healthpromotion/ conferences/9gchp/healthy-china/en/ (accessed September 4, 2020.

65 Lobelo F, Rohm YD, Sallis R, Garber MD Billinger SA, Duperly J, et al. Routine assessment and promotion of physical activity in healthcare settings: a scientific statement from the American Heart Association. Circulation. 2018;137(18):e495-522.
66 Chen SC, Ueng KC, Lee SH, Sun KT, Lee MC. Effect of t'ai chi exercise on biochemical profiles and oxidative stress indicators in obese patients with type 2 diabetes. J Altern Complement Med. 2010;16(11):1153-9.

67 Chen M, He M, Min X, Pan A, Zhang X, Yao $P$, et al. Different physical activity subtypes and risk of metabolic syndrome in middleaged and older Chinese people. PLoS One. 2013;8(1):e53258.

68 Finkelstein EA, Brown DS, Brown DR, Buchner DM. A randomized study of financial incentives to increase physical activity among sedentary older adults. Prev Med. 2008;47(2): 182-7.

69 Danubio ME, Miranda G, Vinciguerra MG, Vecchi E, Rufo F. Comparison of self-reported and measured height and weight: implications for obesity research among young adults. Econ Hum Biol. 2008;6(1):181-90.

70 Hodge JM, Shah R, Mccullough ML, Gapstur SM, Patel AV. Validation of self-reported height and weight in a large nationwide cohort of U.S. adults. PLoS One. 2020;15(4): e0231229.

71 Winckers ANE, Mackenbach JD, Compernolle S, Nicolaou M, van der Ploeg HP, De Bourdeaudhuij I, et al. Educational differences in the validity of self-reported physical activity. BMC Public Health. 2015;15(1):1-5. 